\title{
Leukemia Inhibitory Factor Augments Neurotrophin Expression and Corticospinal Axon Growth after Adult CNS Injury
}

\author{
A. Blesch, ${ }^{1}$ H. S. Uy, ${ }^{1}$ R. J. Grill, ${ }^{1}$ J.-G. Cheng, ${ }^{3}$ P. H. Patterson, ${ }^{3}$ and M. H. Tuszynski ${ }^{1,2}$ \\ ${ }^{1}$ Department of Neurosciences-0626, University of California, San Diego, La Jolla, California 92093, 2Veterans \\ Administration Medical Center, San Diego, California 92165, and 'Bivision of Biology, California Institute of Technology, \\ Pasadena, California 91125
}

\begin{abstract}
The cytokine leukemia inhibitory factor (LIF) modulates glial and neuronal function in development and after peripheral nerve injury, but little is known regarding its role in the injured adult CNS. To further understand the biological role of LIF and its potential mechanisms of action after CNS injury, effects of cellularly delivered LIF on axonal growth, glial activation, and expression of trophic factors were examined after adult mammalian spinal cord injury. Fibroblasts genetically modified to produce high amounts of LIF were grafted to the injured spinal cords of adult Fischer 344 rats. Two weeks after injury, animals with LIF-secreting cells showed a specific and significant increase in corticospinal axon growth compared with control animals. Furthermore, expression of neurotrophin-3, but not
\end{abstract}

nerve growth factor, brain-derived neurotrophic factor, glia cell line-derived neurotrophic factor, or ciliary neurotrophic factor, was increased at the lesion site in LIF-grafted but not in control subjects. No differences in astroglial and microglial/macrophage activation were observed. Thus, LIF can directly or indirectly modulate molecular and cellular responses of the adult CNS to injury. These findings also demonstrate that neurotrophic molecules can augment expression of other trophic factors in vivo after traumatic injury in the adult CNS.

Key words: leukemia inhibitory factor; LIF; gene therapy; corticospinal; spinal cord injury; regeneration; neurotrophic factors
After injury in the nervous system, a wide spectrum of cellular and molecular responses are induced, including changes in trophic factor expression. The precise functions of these growth and differentiation factors after injury are still largely unknown, particularly within the CNS. Studies of regeneration in the peripheral nervous system (PNS) indicate that several factors implicated in growth and differentiation are upregulated after injury and during regeneration (Funakoshi et al., 1993; Kiefer et al., 1993; Banner and Patterson, 1994). One of the factors that might be important for successful regrowth of injured sensory and motor axons in the PNS is leukemia inhibitory factor (LIF). Several recent reports indicate a role for LIF in the response to nervous system damage and during PNS regeneration in the neonatal (Cheema et al., 1994a,b) and adult rat (Hendry et al., 1992; Banner and Patterson, 1994; Curtis et al., 1994; Tham et al., 1997). LIF is upregulated in Schwann cells after adult PNS injury (Banner and Patterson, 1994; Curtis et al., 1994; Sun et al., 1994; Kurek et al., 1996), its retrograde transport to the cell bodies of sensory and motor neurons is increased after nerve lesions (Hendry et al., 1992; Curtis et al., 1994), and this cytokine is required for appropriate changes in neuronal gene expression after injury (Rao et al., 1993; Sun and Zigmond, 1996). Moreover, LIF promotes the survival and outgrowth of sensory and motor neu-

\footnotetext{
Received Nov. 17, 1998; revised Feb. 2, 1999; accepted Feb. 16, 1999.

This work was supported by grants from Veterans Affairs, the National Institute of Neurological Disorders and Stroke (NS37083), the National Institute for Aging (AG10435), the American Paralysis Association, National Institutes of Health (NS 20916 to P.H.P.), and the Deutsche Forschungsgemeinschaft (A.B). We express our appreciation to Dr. Silke Thode for providing selected primer sequences.

Correspondence should be addressed to Dr. Mark Tuszynski, Department of Neurosciences-0626, University of California-San Diego, 9500 Gilman Drive, La Jolla, CA 92093-0626.

Copyright (C) 1999 Society for Neuroscience $\quad 0270-6474 / 99 / 193556-11 \$ 05.00 / 0$
}

rons in vitro and after axotomy in vivo (Arakawa et al., 1990; Martinou et al., 1992; Cheema et al., 1994a,b; Tham et al., 1997). Recently, injury to the adult CNS has also been reported to induce upregulation of LIF expression (Minami et al., 1991; Banner et al., 1997). Increased amounts of LIF mRNA are observed in the postepileptic hippocampus (Minami et al., 1991) and in astrocytes and microglia after cortical lesions (Banner et al., 1997). However, the functional significance of these increases in LIF expression is unknown.

Potential clues regarding functional roles of LIF after nervous system injury are suggested from studies of LIF-modulated properties in the developing nervous system (for review, see Patterson, 1994; Murphy et al., 1997). LIF can regulate neurotransmitter and neuropeptide expression in sympathetic neurons (Yamamori et al., 1989). Furthermore, LIF may influence the survival and maintenance of spinal cord motor neurons (Martinou et al., 1992; Richards et al., 1996; Sendtner et al., 1996) as well as dorsal root ganglion and nodose ganglion sensory neurons (Murphy et al., 1991, 1994; Hendry et al., 1992; Thaler et al., 1994). LIF can also act on astrocytes, oligodendrocytes, and microglia. For example, knockout mice lacking LIF or LIF receptors show reduced numbers of glial fibrillary acid protein (GFAP)-positive astrocytes and display reduced levels of myelin basic protein (Ware et al., 1995; Bugga et al., 1998). In vitro primary astrocyte cultures produce and secrete LIF (Aloisi et al., 1994; Murphy et al., 1995), and LIF can affect the differentiation of oligodendrocyte type-2 astrocyte (O-2A) progenitor cells into astrocytes and alter oligodendrocyte survival after trophic factor deprivation (Barres et al., 1993; Kahn and De Vellis, 1994; Mayer et al., 1994; Gard et al., 1995; Richards et al., 1996). In vitro LIF has also been reported to increase expression of microglial-specific cell markers (Hagg et al., 1993). Outside the nervous system, LIF modulates interleukin 
expression in a model of skin inflammation (Banner et al., 1998). Taken together, these data suggest that LIF might influence nervous system responses to injury by (1) acting directly on neurons, (2) modifying astrocyte function (as shown recently for CNTF) (Kahn et al., 1995; Lisovoski et al., 1997), or (3) influencing inflammation, including microglial responses (Hagg et al., 1993; Patterson et al., 1997; Banner et al., 1998). To date, however, the potential role of exogenous LIF in modulating adult CNS responses to injury has not been investigated.

Using a cellular delivery approach, we determined whether LIF influenced CNS responses to trauma. Effects of cellularly delivered LIF on neurite outgrowth, glial activation, and trophic factor expression after spinal cord injury in adult rats were examined. Fibroblasts genetically modified to express augmented amounts of LIF were grafted to the dorsally hemisected spinal cord; embedded in a collagen matrix, these grafts provided both LIF and potential "bridges" to regenerating neurites that are specifically and focally targeted to the injury site (Tuszynski et al., 1996; Grill et al., 1997). Previously we have reported the usefulness of this model in examining axonal growth responses in the injured spinal cord to other cellularly delivered growth factors, including nerve growth factor (NGF) and neurotrophin-3 (NT-3) (Tuszynski et al., 1996; Grill et al., 1997). In the present study we report that cellular sources of LIF enhance outgrowth of a specific class of injured spinal cord axons and upregulate expression of the neurotrophin NT-3 in the spinal cord, yet they do not alter morphological features of glial cell reactivity after injury.

\section{MATERIALS AND METHODS}

Construction of retroviral vectors. The rat LIF cDNA was amplified by PCR using the 5' LIF primer TGTGAATTCGCCACCATGAAGGTCTTGGCCGCAGGGATT containing an EcoRI site and a Kozak consensus sequence and the $3^{\prime}$ LIF primer TGTGGATCCCTAGAAGGCCTGGGCCAACACACT including a Bam HI site. The PCR product was digested with $E c o \mathrm{RI} / B a m \mathrm{HI}$ and ligated into the retroviral vector pLXSN. A retroviral producer cell line was established as described using the ecotropic cell line psi-2 and the amphotropic cell line PA 317.

The LIF transgene was constitutively driven by the $5^{\prime}$ LTR, and a dominant selectable marker imparting neomycin resistance was expressed by the $S V 40$ promoter, as described previously (Tuszynski et al., 1996; Grill et al., 1997). Primary rat fibroblasts transfected with Escherichia coli $\beta$-galactosidase were used as controls.

Cell culture. Primary cultures of Fischer 344 rat fibroblasts were generated as described previously (Tuszynski et al., 1996).

In vitro characterization of LIF-secreting fibroblasts. LIF gene expression in transduced primary fibroblasts was assessed by Northern blotting. Twenty micrograms of total RNA were separated on a $1 \%$ formaldehyde-agarose gel, transferred to a nylon membrane, and hybridized to a ${ }^{32} \mathrm{P}$-labeled rat LIF cDNA fragment. After two washes in $1 \times \mathrm{SSC}(150$ $\mathrm{mm} \mathrm{NaCl}, 15 \mathrm{~mm}$ sodium citrate) with $0.1 \%$ SDS for $1 \mathrm{hr}$ each at $65^{\circ} \mathrm{C}$, blots were exposed to x-ray film.

For determination of LIF protein levels, serum-free supernatants were collected from confluent monolayers of LIF- and $\beta$-galactosidaseproducing fibroblasts and concentrated by filter centrifugation $(10,000$ NMWL filter units; Millipore, Bedford, MA). Proteins were separated on a $10 \%$ SDS-polyacrylamide gel and transferred to a polyvinylidene difluoride membrane (Millipore). After blocking for $1 \mathrm{hr}$ in 1\% BSA in TBS/0.25\% Tween 20, blots were incubated overnight with a polyclonal anti-LIF antibody (1:2000; Santa Cruz Biotechnology, Santa Cruz, CA), followed by a secondary alkaline phosphatase-conjugated antibody (1: 5000; Life Technologies, Bethesda, MD).

Bioactivity of LIF secreted into the supernatant from transfected cells was tested by coculturing the erythroleukemia cell line TF-1 (Kitamura et al., 1989; Davis et al., 1993) with LIF-transfected and controltransfected fibroblasts, respectively. In this assay, TF-1 cells show increased proliferation in response to LIF. LIF-expressing cells were seeded into 24 -well plates and cocultured with TF- 1 cells $\left(4 \times 10^{4}\right.$ cells per well) starting $48 \mathrm{hr}$ later by plating TF-1 cells into cell culture inserts
(Nunc, Naperville, IL). The number of viable TF-1 cells was counted 48 hr later using the trypan blue exclusion assay.

Experimental subjects. Female Fischer 344 rats weighing 160-200 gm (Harlan Sprague Dawley) were housed three per cage with free access to food and water. National Institutes of Health guidelines for laboratory animal care and safety were strictly followed. Animals were killed 2 weeks after lesion/grafting surgery.

Lesion surgery. T7 dorsal laminectomies were performed on deeply anesthetized rats [anesthetic mixture $(2 \mathrm{ml} / \mathrm{kg})$ : ketamine $25 \mathrm{mg} / \mathrm{ml}$, rompun $1.3 \mathrm{mg} / \mathrm{ml}$, and acepromazine $0.25 \mathrm{mg} / \mathrm{ml}$ ], as described previously (Grill et al., 1997). Briefly, the dura was opened, the dorsal cord midline was superficially incised, and the dorsal columns were removed using a fine-tipped glass-pulled aspiration device. The lesion was continued ventrally until all dorsal white matter was removed and then extended slightly more ventrally to complete the hemisection in the central cord region. Using this central lesion as a guide for the desired dorsoventral depth of the lesion, the lesion was extended laterally to remove the lateral aspects of the cord. In this procedure, both dorsal halves of the spinal cord are removed, leaving the ventral halves of the cord unaffected by the lesion (Grill et al., 1997).

For in vivo grafting, LIF-secreting genetically modified fibroblasts $(n=$ 24 animals) or control fibroblasts $(n=24$ animals $)$ were embedded in type I collagen gels (Sigma, St. Louis, MO) as described previously (Tuszynski et al., 1996). Briefly, primary transduced cells were harvested by gentle trypsinization and suspended at a concentration of $2.1 \times 10^{6}$ cells $/ \mathrm{ml}$ in $1 \mathrm{ml}$ liquid collagen type I (Sigma) solution. After $24 \mathrm{hr}$ incubation at $37^{\circ} \mathrm{C}$, gelatinous collagen blocks containing transduced cells were trimmed and grafted to spinal cord lesion sites immediately after the dorsal hemisection was performed. Overlying muscular layers were sutured, and cutaneous layers were stapled. After the operation, animals received manual bladder evacuation and 20,000 $\mathrm{U} / \mathrm{kg}$ ampicillin twice daily for $10 \mathrm{~d}$ to prevent and treat urinary tract infections. Lesion extent was verified by observing (1) complete interruption of the main body of the dorsal corticospinal tract anterogradely labeled with wheat germ agglutinin-conjugated horseradish peroxidase (WGA-HRP) injected into the sensorimotor cortex (see below), or (2) that the dorsal half of the spinal cord had been completely removed as determined on serial Nissl-stained sagittal sections in all subjects.

Anterograde labeling of the corticospinal tract projection. Two weeks after lesion and grafting surgery, WGA-HRP (300 nl of a 4\% solution) was injected through pulled-glass micropipettes $(40 \mu \mathrm{m}$ internal diameter) into each of 12 sites per hemisphere spanning the rostrocaudal extent of the rat sensorimotor cortex using a PicoSpritzer II (General Valve, Fairfield, NJ), as described previously (Grill et al., 1997). Labeling was performed in eight LIF-grafted animals and in eight animals with control grafts. Animals were transcardially perfused $48 \mathrm{hr}$ later with $1 \%$ paraformaldehyde $1.25 \%$ glutaraldehyde followed by $10 \%$ buffered sucrose. Sections $(35 \mu \mathrm{m}$ thick) were cut in the sagittal plane. Six of every seven sections were reacted with a modification of the tetramethyl benzidine method (Grill et al., 1997) and quantified in a blinded manner (see below). The remaining one of seven sections were Nissl-stained.

Quantification of corticospinal tract growth after injury. The density of WGA-HRP reaction product was quantified in the gray matter under light-field illumination at the level of the lesioned corticospinal tract and in an adjacent field $0.8 \mathrm{~mm}$ distal to the most caudal aspect of the lesioned corticospinal tract (CST). Nonspecific labeling products, including random TMB crystals adhering to the lesion site, residual red blood cells in the interstitial space, or any TMB crystals that were not oriented in association with axonal profiles, were edited from digitized images before quantification. Editing was essential to ensure that the quantified images accurately reflected the WGA-HRP-labeled sections. The system operator was blinded to the nature of the experimental group while editing and all other aspects of analysis were conducted. The number of pixels occupied by reaction product in the gray matter was quantified using NIH Image software on a video image of each $100 \times$ magnified section transmitted by a high-resolution Sony CCD camera. Thresholding values in NIH Image were chosen such that only TMB reaction product resulted in measurable pixels on the digitized image; light nonspecific background labeling was not detected. Contrast between reaction product and background was maximized and held constant between all subjects.

A fixed box size of $640 \times 480$ pixels was used to measure the number of pixels containing WGA-HRP reaction product in every labeled sagittal section of spinal cord gray matter beginning precisely at the level of the spinal cord lesion site, at $100 \times$ magnification. The sample box did not 
A

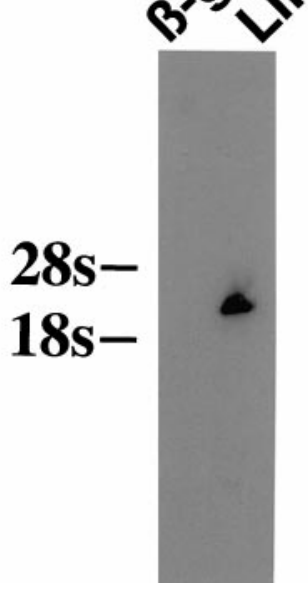

B
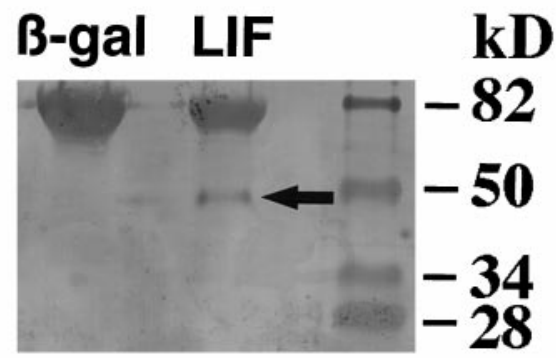

c

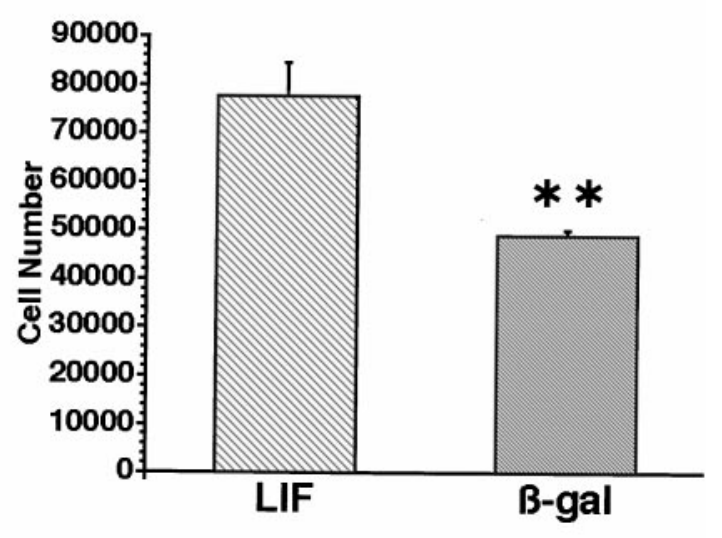

Figure 1. Characterization of LIF-expressing fibroblasts. $A$, Northern blot showing LIF RNA expression in LIF-transfected but not in controltransfected cells. LIF, LIF- expressing cells; $\beta$-gal, $\beta$-galactosidase-expressing cells. $B$, Western blot. A band of $45 \mathrm{kDa}$ is visible in LIF-transfected (arrow) but not in control-transfected fibroblasts. The molecular weight of the marker proteins is indicated in lane 3 . $C$, Growth of TF-1 cells is significantly higher when cocultured with LIF-transfected fibroblasts than with control $\beta$-gal-expressing cells. $p<0.01$; mean \pm SEM.
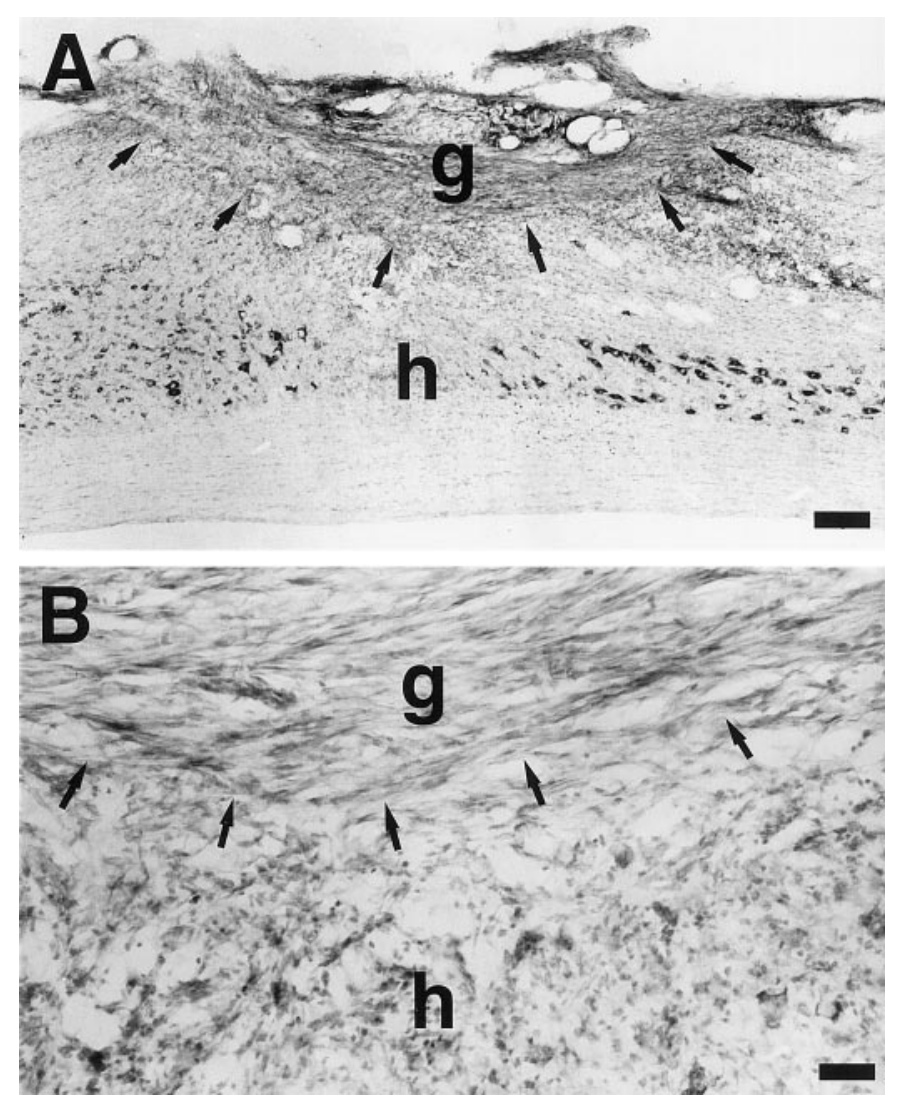

Figure 2. Integration of grafted fibroblasts into the host spinal cord. $(A)$ Low- and $(B)$ high-magnification view of Nissl-stained sagittal sections show numerous surviving grafted fibroblasts 2 weeks after grafting that span the dorsal hemisection lesion cavity (arrows) and provide a potential tissue bridge for growing axons. There is excellent graft integration into the lesion site. Arrows indicate host/graft interface. An LIF-secreting cell graft is pictured. $g$, Graft; $h$, host. Scale bars: $A, 230 \mu \mathrm{m} ; B, 45 \mu \mathrm{m}$. include the graft itself because WGA-HRP-labeled axons were not detected within grafts (see Results). The sample box spanned the complete dorsal-to-ventral extent of the gray matter in the sampled region. Total labeled pixels from every measured section at the lesion site per subject (a series of six-in-seven sections per animal through the entire thickness of the spinal cord) were summed, and a total value per subject was thereby generated. Measured pixels were divided by the area of the sampled region to obtain the relative HRP labeling intensity per pixel. Similar measurements were made for each subject $0.8 \mathrm{~mm}$ caudal to the lesion site. To correct for differences in HRP labeling efficiency between animals, the density of the labeled main CST was measured at a point 1.5 $\mathrm{cm}$ rostral to the lesion site in the three most intensely labeled sections in each subject, using a box size of $640 \times 300$ pixels; this pixel value was divided by the total sampled area in this region to obtain the relative baseline WGA-HRP labeling density measurement (BLDM) value per subject. The total labeled pixels per unit area at the lesion site and, separately, $0.8 \mathrm{~mm}$ below it, were then divided by the BLDM value of that subject. These corrected values were compared between animals to determine a specific and direct measurement of CST growth. Although few axons in the ventral component of the corticospinal tract were labeled by WGA-HRP in this experiment, their numbers were also quantified in all labeled sections.

Immunolabeling. Animals used for immunolabeling were transcardially perfused with $100 \mathrm{ml}$ cold $0.1 \mathrm{M}$ PBS followed by $300 \mathrm{ml} 4 \%$ paraformaldehyde in phosphate buffer. Spinal cords were removed, post-fixed overnight in $4 \%$ paraformaldehyde, and then left for at least $2 \mathrm{~d}$ in phosphate buffer containing $30 \%$ sucrose at $4^{\circ} \mathrm{C}$. Sagittal sections were cut at $35 \mu \mathrm{m}$ intervals with a cryostat. Every seventh section was immediately mounted on glass slides for Nissl staining. Remaining sections were processed with immunocytochemical labels directed against the following markers: neurofilament (RT97; 1:250; Boehringer Mannheim, Indianapolis, IN) to detect general axonal growth; choline acetyltransferase (ChAT) (1:1000, Chemicon, Temecula, CA) to label motor axons; tyrosine hydroxylase (TH) (1:5000; Eugenetech, Ridgefield Park, NJ) to detect growth of axons directly extending from the coerulospinal tract; serotonin (5-HT) (1:35,000; Chemicon) to label raphaespinal axons; calcitonin gene-related peptide (CGRP) (1:8000; Chemicon) to label primary sensory axons; GFAP (1:250; Boehringer Mannheim) to label astrocyte soma and processes; and OX-42 (1:1000; Harlan Bioproducts, Indianapolis, IN) to label macrophages/microglia. All immunocytochemical labeling was performed using free-floating sections in the following protocol: (1) overnight incubation in primary antibody at $4^{\circ} \mathrm{C},(2)$ incubation for $1 \mathrm{hr}$ with biotinylated secondary antibodies (1:200; Vector Laboratories, Burlingame, CA) at room temperature, (3) $1 \mathrm{hr}$ incubation with avidin-biotinylated peroxidase complex (1:100; Vector Elite Kit) at room temperature, and (4) treatment for 3-15 min with $0.05 \%$ solution of 


\section{LIF}

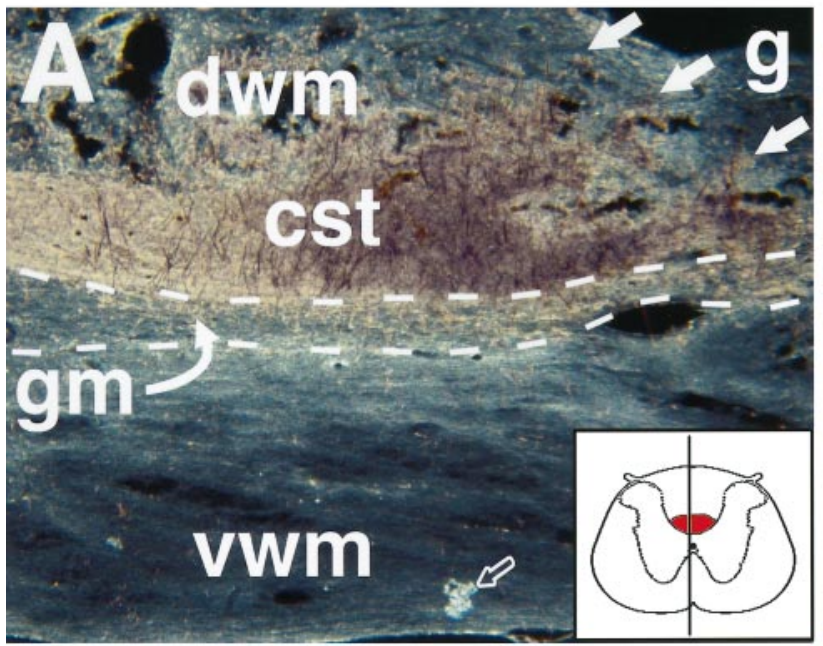

6

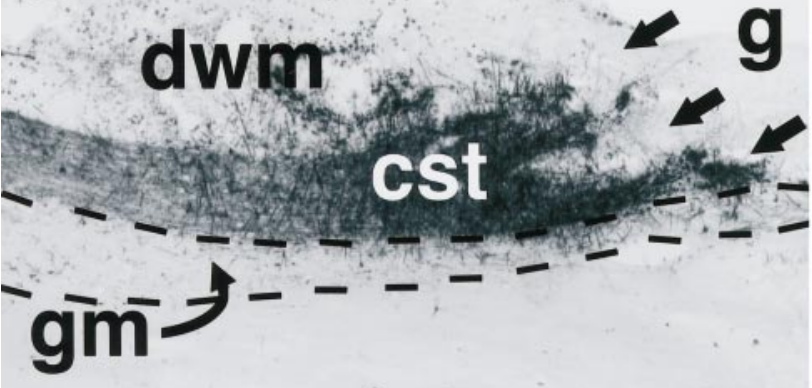

VWm

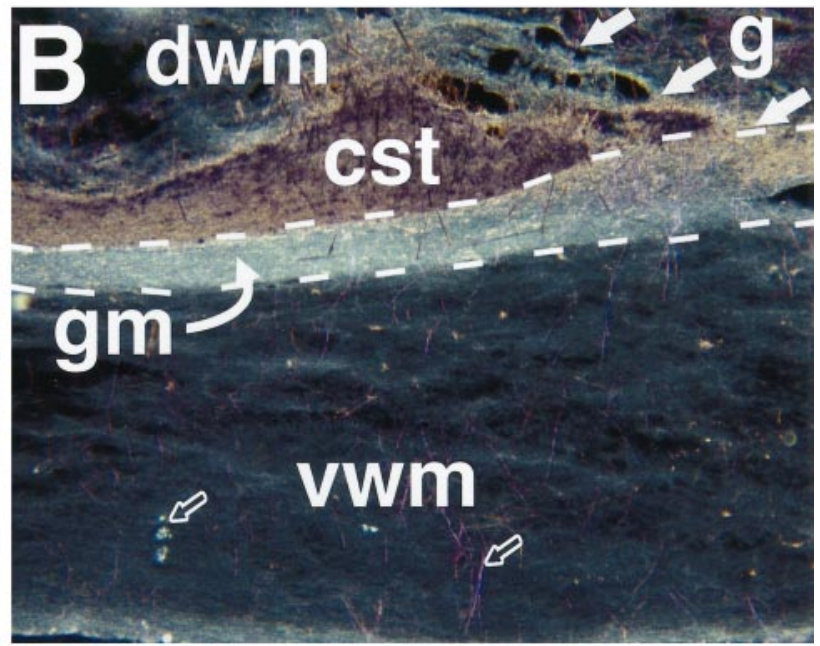

\section{Control}

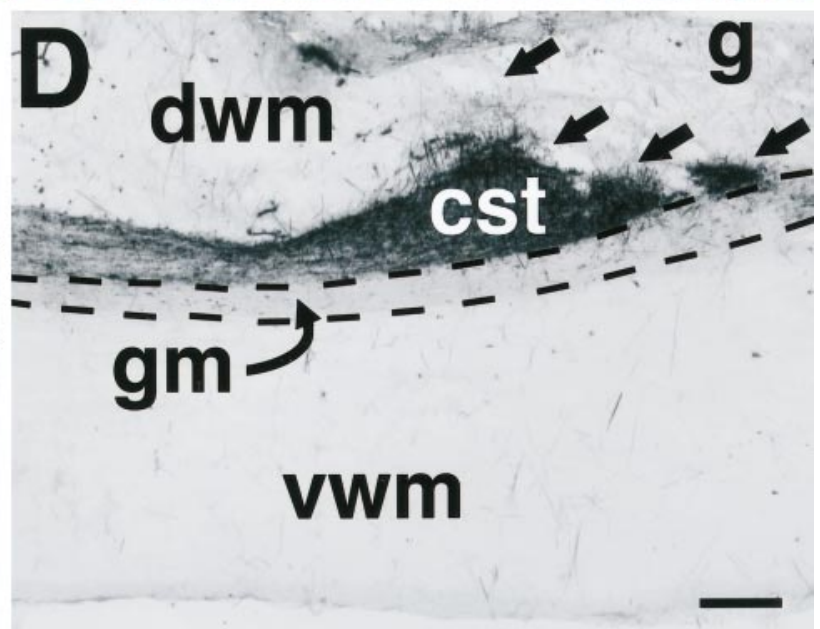

Figure 3. WGA-HRP labeling of the main corticospinal tract. Dark-field $(A, B)$ and light-field $(C, D)$ illumination show that the labeling intensity of the main corticospinal tract (cst) rostral to the injury site is similar in LIF-grafted $(A, C)$ and control-grafted $(B, D)$ animals. There is no significant retraction of CST axons from the lesion site at this time point ( 2 weeks after injury and grafting). Inset in $A$ shows the approximate mediolateral location of the sections, indicating a relatively thin strip of central gray matter and wide strips of dorsal and ventral white matter; the red portion of inset indicates the position of the dorsal CST. Scale bar: $A, B, 172 \mu \mathrm{m} ; C, D, 220 \mu \mathrm{m}$. Host/graft interface is outlined by straight, filled arrows; the border between dorsal white matter $(\mathrm{dwm})$, gray matter $(\mathrm{gm})$, and ventral white matter $(\mathrm{vwm})$ is indicated by dashed lines. $g$, Graft. Open arrows in $A$ and $B$ indicate the type of artifacts that were edited from digitized images before quantification of WGA-HRP grain density (see Materials and Methods).

3.3' diaminobenzidine, $0.01 \% \mathrm{H}_{2} \mathrm{O}_{2}$, and $0.04 \%$ nickel chloride at room temperature.

Quantification of GFAP expression. The density of GFAP labeling was quantified in white matter and separately in gray matter, directly ventral to the lesion site in three LIF- and three control-grafted animals. A minimum of four sections randomly selected from the lesion site were analyzed per animal under light-field illumination using NIH image software and a digital camera similar to that described above for WGAHRP labeling. Pixel values in a fixed box size of $640 \times 480$ were averaged for each animal to obtain a measurement of GFAP-labeling density per unit area in white and gray matter, respectively.

$R T-P C R$. Two weeks after grafting RNA was isolated from LIFgrafted $(n=3)$ and control-grafted animals $(n=3)$. Fresh spinal cord (3-4 $\mathrm{mm}$ ) containing the graft was excised and immediately frozen. Acidic phenol/chloroform extraction was used to extract RNA, and 500 ng RNA were reverse-transcribed in a total volume of $20 \mu \mathrm{l}$ according to the manufacturer's instructions (Boehringer Mannheim). Two microliters of the first-strand synthesis were used for each PCR. The $50 \mu \mathrm{l} \mathrm{PCR}$ reaction additionally contained $0.5 \mu \mathrm{g}$ of each primer, $1.5 \mathrm{mM} \mathrm{MgCl}_{2}, 50$ mu KCl, 10 mm Tris-HCl, pH 9.0, 0.1\% Triton X-100, 0.2 mm dNTP, 2.5 $\mu \mathrm{Ci}{ }^{32} \mathrm{P}$-dCTP, and $2.5 \mathrm{U}$ Taq-polymerase (Promega, Madison, WI) Amplification was performed at the following temperature profile: $60 \mathrm{sec}$ at $94^{\circ}, 30 \mathrm{sec}$ at $60^{\circ} \mathrm{C}, 60 \mathrm{sec}$ at $72^{\circ} \mathrm{C}$. The number of cycles for each primer pair (except LIF) was first determined to be in the logarithmic phase of amplification using RNA from spinal cords of unoperated controls to establish standards. The number of cycles used were 24 cycles for RPL27, 27 cycles for LIF, 28 cycles for NGF, 30 cycles for NT-3, 26 cycles for ciliary neurotrophic factor (CNTF), 30 cycles for glia cell line-derived neurotrophic factor (GDNF), and 27 cycles for brainderived neurotrophic factor (BDNF). Controls for PCR included omitting reverse transcriptase from the first-strand synthesis and completely omitting template from the PCR; in the case of both PCR controls, no amplification products were visible.

Primers used were as follows: LIF: see construction of retroviral vectors; RPL27: 5'-AGAACATTGATGATGGCACC-3' and 5'-ATATCCACAGAGTACCTTGT-3'; NGF: 5'-GCAGTGCCCCTGCTGAACCA-3' and 5'-AAACAGCACGCGGGGTGAAC-3'; BDNF: 5'-GGAGCTGAGCGTGTGTGACA-3' and 5'-CGGGACTTTCTCCAGGACT-3'; NT-3: 5'-TGCCATGGTTACTTCTGCCACG-3' and 5'-GGATGCCACG- 


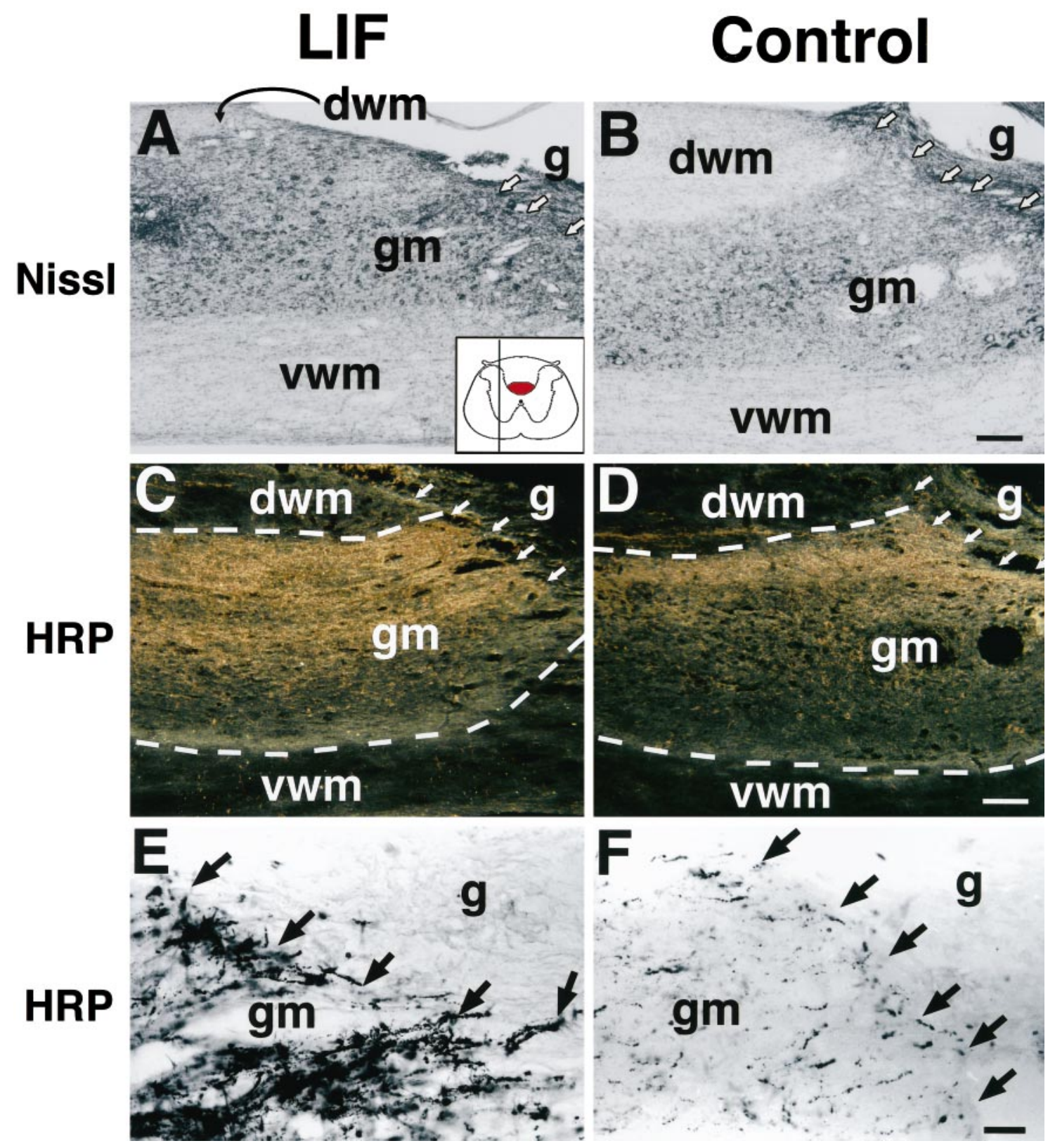

Figure 4. Enhanced growth of lesioned corticospinal tract axons in LIF-grafted animals. Nissl stains $(A, B)$ show the relative amounts of host gray matter and white matter in sections close to those pictured in $C-F$. $A$, LIF-grafted subject; $B$, control-grafted subject. $d w m$, Dorsal white matter; $g m$, gray matter; $v w m$, ventral white matter. Arrows indicate host/graft $(g)$ interface. Inset in $A$ demonstrates that these sections are sampled from regions lateral to the midline; thus, dorsal white matter containing the CST (red in inset) is no longer visible in these sections. WGA-HRP-labeled sections $(C-F)$ demonstrate substantially augmented growth of WGA-HRP-labeled CST axons up to the host/graft interface in host gray matter ventral to the lesion site in LIF-grafted $(C, E)$ but not in control-grafted $(D, F)$ animals. The preponderance of this growth is located in the more dorsally located gray matter rather than in ventrally located gray matter. In dark-field illumination $(C, D)$, the borders between dorsal white matter $(d v m)$, gray matter $(g m)$, and ventral white matter $(\mathrm{vwm})$ can be readily distinguished (indicated by dashed lines). Linear arrays of CST axons of the sort present in the gray matter of these lesioned spinal cords $(E, F)$ are detectable only after injury; normally, CST-labeled ramifications in the gray matter exhibit numerous arborizations of fine, varicose axons but not linear growth. Scale bars: $A, B, 220 \mu \mathrm{m} ; C, D, 172 \mu \mathrm{m} ; E, F, 42 \mu \mathrm{m}$.

GAGATAAGCAAG-3'; CNTF: 5'-CTCTGTAGCCGTTCTATCTG-3' and 5'-GAGTATGTATTGCCTGATGG-3'; GDNF: 5'-CGGTAAGAGGCTTCTCGAAG-3' and 5'-CGCTTGTTTATCTGGTGACC-3'.

Twenty microliters of the PCR reaction product were separated on an $8 \%$ polyacrylamide gel. The gel was dried and exposed to x-ray film for different times until the signals were visible but the silver grains on the film were not saturated. Signals on x-ray films were quantified using the NIH Image gel plot macro. Expression of different genes was quantified relative to the mRNA levels of the ribosomal housekeeping control gene RPL27.

Statistical analysis. All data were analyzed using unpaired Student's $t$ test (two-tailed) at a 95\% significance level. Statview software was used to conduct statistical analysis.

\section{RESULTS}

Retroviral vectors were constructed for infection of primary rat fibroblasts with rat LIF or a $\beta$-galactosidase reporter gene coding sequence. The $5^{\prime}$ long terminal repeat was used as a promoter for transgene expression. Fibroblasts genetically modified to produce LIF showed strong RNA expression as demonstrated by Northern 

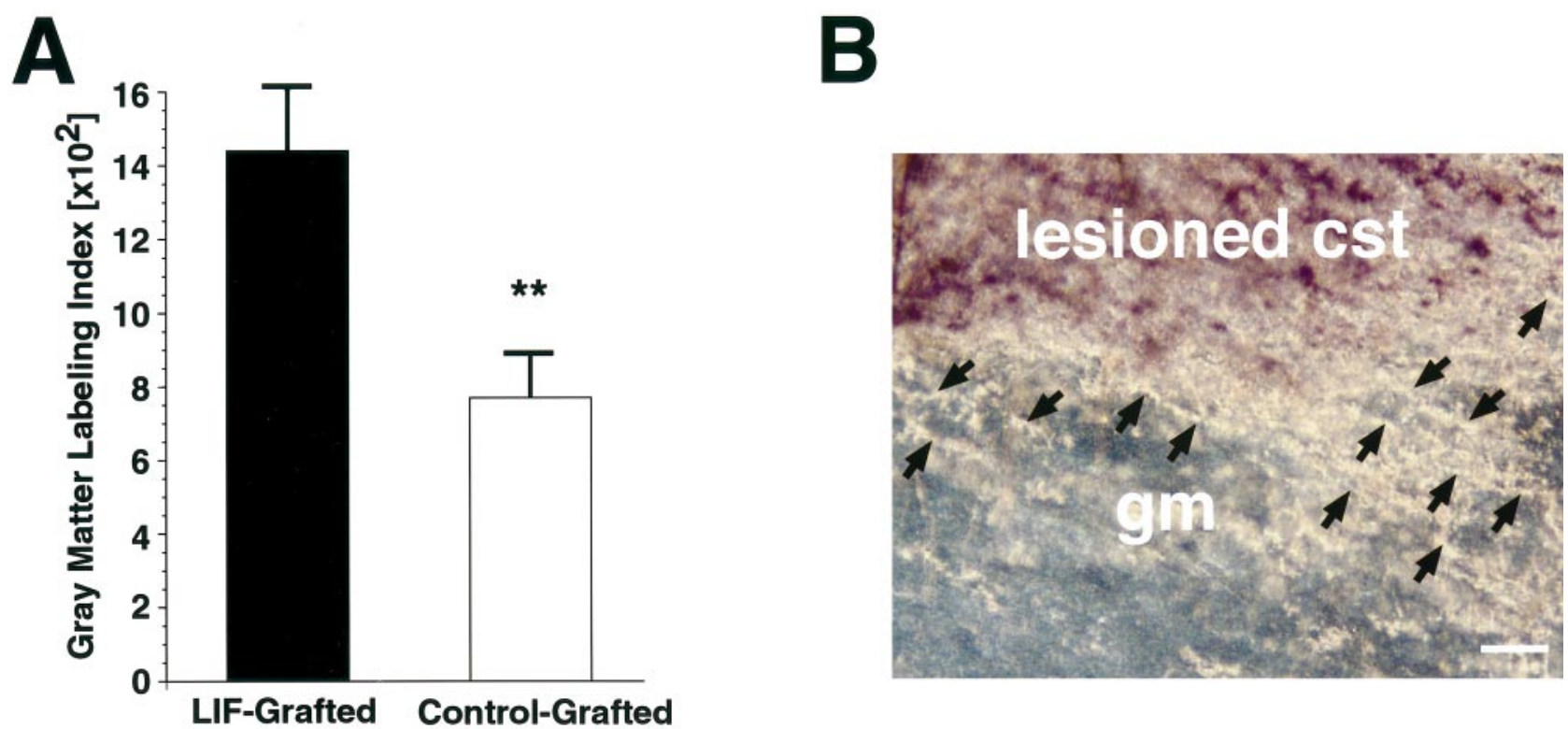

Figure 5. A, Quantification of corticospinal WGA-HRP-labeled processes in spinal cord gray matter. At the lesion site, there is a significant increase in the number of WGA-HRP-labeled axonal processes in LIF-grafted recipients $(p<0.01$; mean $\pm \mathrm{SEM})$. At this relatively brief time point, growth is not increased in an adjacent field $0.8 \mathrm{~mm}$ distal to the lesion. Labeling was quantified as described in Materials and Methods. $B$, Extending corticospinal tract axons originate from the lesioned dorsal CST. Dark-field photomicrograph from LIF-grafted subject demonstrates WGA-HRPlabeled axons extending linear profiles from the dorsal lesioned corticospinal tract (lesioned cst) into the underlying gray matter ( gm) at the lesion site. Arrows indicate individual axons. Scale bar, $34 \mu \mathrm{m}$.

blot (Fig. 1A). Supernatants of transfected cells contained a protein of appropriate $M_{\mathrm{r}}$ of $45 \mathrm{kDa}$, which bound a polyclonal anti-LIF antibody in Western blot (Fig. $1 B$ ). No LIF protein or mRNA could be detected in primary control-transfected fibroblasts. The bioactivity of secreted LIF in the cell culture supernatants was tested by co-culture with the LIF-responsive cell line TF-1 (Kitamura et al., 1989;Davis et al., 1993). Growth of TF-1 cells was significantly higher when co-cultured with LIFtransfected than with control-transfected fibroblasts (Fig. 1C) $(p<0.01)$.

To investigate the effects of continuous localized LIF delivery on injured axon growth in the spinal cord, LIF-secreting or control $\beta$-galactosidase-producing cells were embedded in a collagen matrix and grafted to the dorsally hemisected spinal cord ( $n=24$ LIF-secreting graft recipients and 24 control graft recipients). Fibroblast grafts integrated into host tissue and showed good survival for the 2 week period examined in this study (Fig. 2). All animals showed complete lesions as judged by interruption of anterograde transport of WGA-HRP in the dorsal corticospinal tract and lesion extension through at least half of the dorsalto-ventral extent of the spinal cord on Nissl-stained sections.

Of note, recipients of LIF-secreting cell grafts exhibited a significant increase in CST growth compared with control-grafted subjects at the level of the lesion $(p<0.01)$, as determined by quantification of CST axons anterogradely labeled with WGAHRP (Figs. 3-5). Nearly twice as many CST axonal processes were detectable in LIF-grafted subjects compared with controlgrafted animals (Figs. 4, 5A). Interestingly, this increase in CST axonal growth occurred through regions of host spinal cord gray matter ventral to the lesion site, rather than extending through the graft itself or through host white matter ventral to the graft site (Fig. $4 C-F$ ). The augmented axonal labeling in the gray matter was derived from axons extending from the main dorsal CST rather than from fibers in the ventral white matter (Fig. $5 B$ ). This increase in CST axon growth through host gray matter at the lesion site in LIF-grafted subjects was also not an artifact of heightened efficiency of WGA-HRP anterograde transport, because labeling intensity of the main CST $1.5 \mathrm{~cm}$ rostral to the lesion site did not differ between LIF-grafted and control-grafted groups (Fig. 3). The main CST in the dorsal funicular white matter had not retracted from the lesion site at this 2 week post-injury time point; corticospinal axonal die-back occurs only at later time points after injury (Schnell and Schwab, 1993; R. Grill, A. Blesch, M. Tuszynski, unpublished observations). At this relatively short time point of 2 weeks after grafting, an increase in CST axon growth through host gray or white matter at a point $0.8 \mathrm{~mm}$ distal to the lesion site was not detected in the LIF-grafted group compared with the control group. Few axons in the ventral component of the corticospinal tract were labeled by WGA-HRP, and no significant differences in the numbers of these ventral axons were present when the LIF and control groups were compared.

Immunolabeling was performed to determine whether other axonal systems also responded to the presence of LIF-secreting cell grafts. No differences in responses of neurofilament-labeled axons, ChAT-labeled motor axons, CGRP-labeled primary sensory axons, 5-HT-labeled serotonergic axons, or TH-labeled coerulospinal axons (Fig. 6) were observed when LIF-grafted and control-grafted subjects were compared. Thus, responses of corticospinal axons to LIF-secreting cell grafts were specific among the systems examined.

Given the apparent specificity of LIF-secreting cell grafts for enhancing growth of the corticospinal projection, RT-PCR was performed to determine whether these grafts influenced the expression of the corticospinal axon growth factor NT-3 (Schnell et al., 1994; Yee and O'Leary, 1996; Grill et al., 1997) or other growth factors, including NGF, BDNF, GDNF, CNTF, and LIF itself (Fig. 7). Host spinal cord containing the graft and the lesion 


\section{LIF}
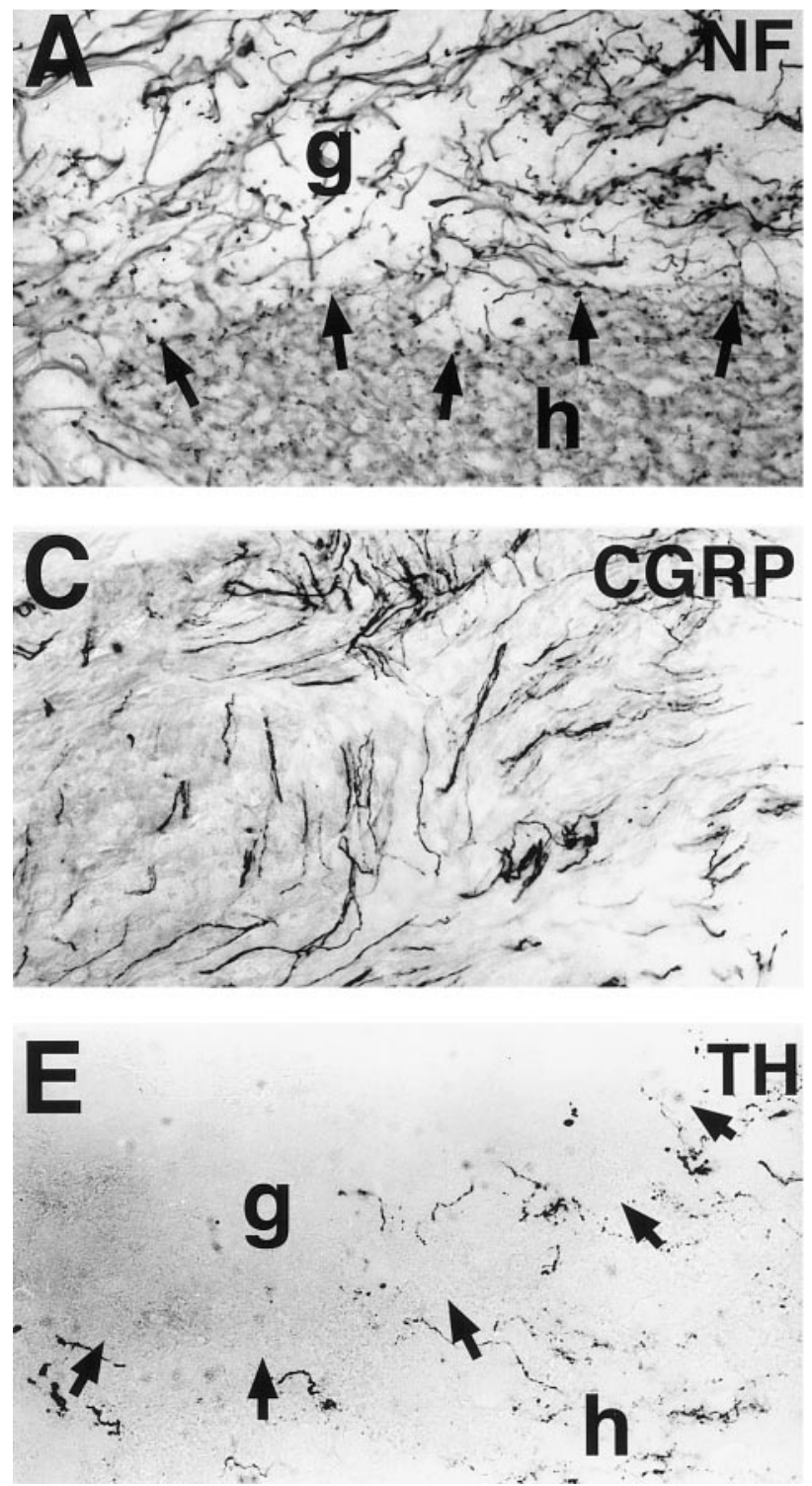

\section{Control}
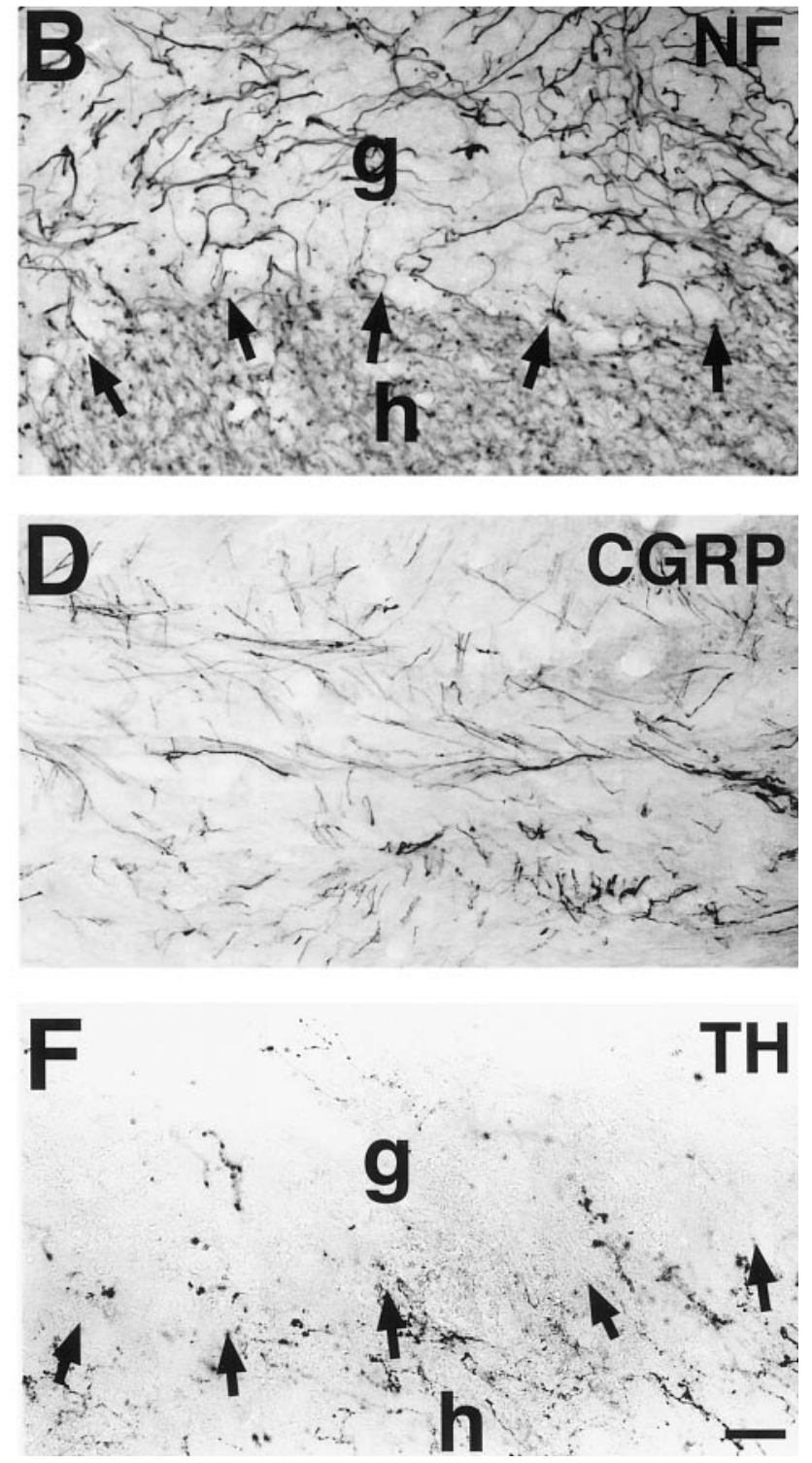

Figure 6. Responses of other axonal systems to LIF-secreting and control grafts. Augmentation in the growth of other axonal systems is not observed in LIF-grafted recipients, indicating specificity of the growth effect to corticospinal systems. Neurofilament labeling $(N F)$ shows no difference in overall axonal penetration into LIF-secreting $(A)$ and control $(B)$ grafts. Neurites that do penetrate grafts are mainly of sensory origin and exhibit immunolabeling for CGRP ( $C$, LIF-secreting graft; $D$, control graft). There is also no difference in penetration of $T H$-labeled coerulospinal axons adjacent to and within grafts ( $E$, LIF-secreting; $F$, control grafts). Similarly, serotonergic and cholinergic axons penetrate grafts to a modest extent that does not significantly differ between graft types (data not shown). Arrows indicate host $(h) / g r a f t ~(g)$ interface. Scale bar: $A, B, 55 \mu \mathrm{m} ; C-F, 42 \mu \mathrm{m}$.

site at a time point 2 weeks after injury was used for RNA isolation, and expression levels were compared between LIFgrafted $(n=3)$ and control-grafted $(n=3)$ animals. The housekeeping ribosomal gene RPL27 was used to normalize RNA amounts among samples. NT-3 gene expression was significantly higher in all animals that received LIF grafts compared with controls. Approximately twofold-higher NT-3 RNA was detectable in LIF-treated animals than in controls. On the other hand, expression levels of NGF, CNTF, GDNF, and BDNF were similar in the two experimental groups. Continuous expression of the LIF transgene over the 2 week experimental period was evident for all sampled LIF-grafted subjects, whereas control- grafted animals did not exhibit any detectable LIF expression. No amplification products were present when reverse transcriptase was omitted from the reaction, indicating that contamination of the RNA preparation by DNA had not occurred.

To determine whether LIF-secreting cell grafts modulated host glial or inflammatory responses, GFAP and OX-42 immunolabeling were performed. GFAP immunolabeling revealed reactive astrogliosis in both LIF-secreting and control cell grafts that did not differ qualitatively at the lesion/graft site in the two groups (Fig. 8A,B). Quantitative densitometry of GFAP immunolabeling using NIH Image also failed to reveal significant differences between LIF- and control-grafted animals adjacent to the lesion 

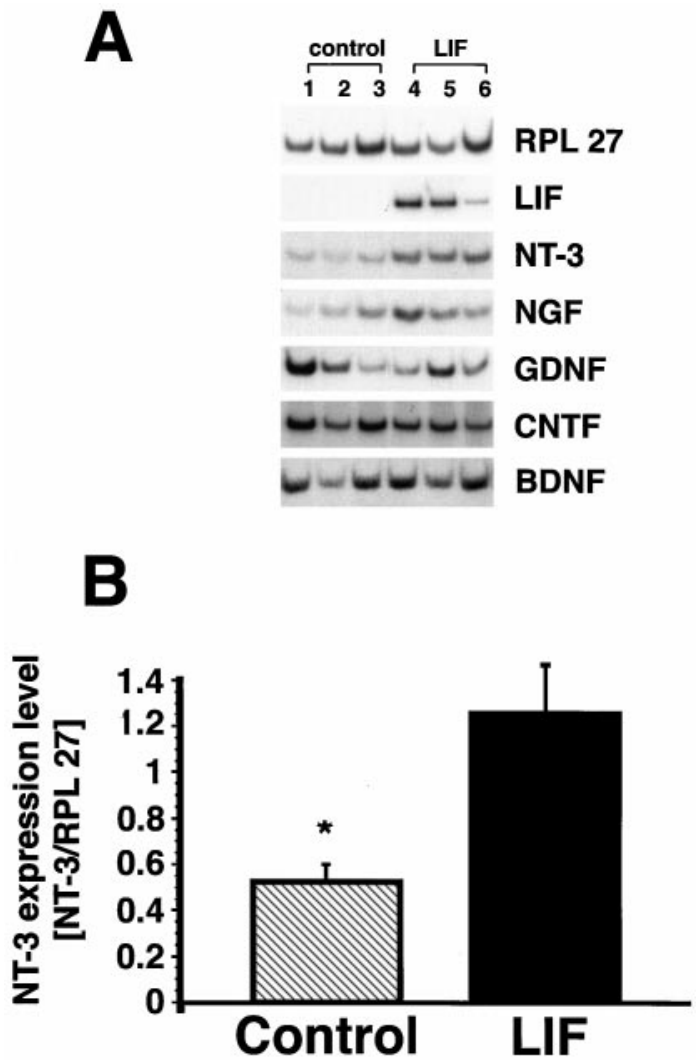

Figure 7. LIF-secreting cells augment NT-3 gene expression in vivo. A, Semiquantitative RT-PCR demonstrates clearly upregulated NT-3 expression in all LIF-grafted animals compared with control-grafted animals. No differences in NGF, BDNF, CNTF, and GDNF expression exist between LIF and control grafts (NGF expression is slightly but not significantly higher). Continued LIF transgene expression is evident in all LIF-grafted animals through the experimental period ( 2 weeks). $B$, Measurement of neurotrophin signal intensity shows significantly higher expression of NT-3 in LIF-grafted compared with control-grafted animals $(p<0.05$ for NT-3; mean \pm SEM $)$. Units for NT-3 expression levels are provided as the ratio of NT-3 to RPL 27 expression, as a means of controlling for small differences in RNA amounts that may be present.

in either white matter or gray matter (white matter: LIF-grafted: $134,650 \pm 10,243$ pixels, control-grafted: $127,652 \pm 17,786$ pixels, $p=0.735$; gray matter: LIF-grafted: $165,970 \pm 12,041$ pixels, control-grafted: $168,964 \pm 2,466$ pixels, $p=0.861$; values are \pm SEM). Relatively few GFAP-labeled glial processes extended into either LIF-secreting or control cell grafts. Immunolabeling for the microglial/macrophage marker OX-42 showed many activated microglia and macrophages in the vicinity of both LIFsecreting and control grafts (Fig. 8). Microglial/macrophage accumulation was present at the host/graft interface, and several OX-42-labeled cells infiltrated both grafts, but differences in the distribution and intensity of OX-42 immunolabeling were not appreciable at a qualitative level when comparing control and LIF-secreting graft recipients within the graft, at the host-graft interface, or in the host spinal cord adjacent to and distant from the injury site. These findings do not exclude the possibility that more subtle differences could be detected by detailed quantification.

\section{DISCUSSION}

The present study demonstrates that the cellular delivery of LIF to the injured adult CNS promotes corticospinal axon growth and increases expression of another growth factor, NT-3. This is the first in vivo demonstration that LIF can modulate responses of the adult CNS to injury and that one neurotrophic factor can influence expression of another after adult CNS trauma. Neurotrophic factors exert broad effects at multiple regulatory levels on cellular function in the adult CNS, including effects on neuronal survival, differentiation, axonal outgrowth, neurotransmitter release, and synaptic efficacy (Eide et al., 1993; Korsching, 1993; Thoenen, 1995; Lewin and Barde, 1996). The present findings support another role of trophic factors in the nervous system: they may regulate nervous system function and response to injury by augmenting the production of other trophic factors. This is particularly interesting when considered in the context of trophic factors that lack secretory signals and may be released from cells at times of injury, including the cytokine growth factor CNTF (a member of the same family as LIF), and fibroblast growth factor-1, which induces NGF expression after cortical infarction (Figueiredo et al., 1995). Such factors could trigger a cascade of secondary neurotrophic factor expression, thereby influencing neural cells that are not directly targeted by the first growth factor. Neurotrophic factor-induced changes in the production of other neurotrophins have also been reported in vitro using PC-12 cells and hippocampal cultures (Cannosa et al., 1997), in the PNS in dorsal root ganglia (Apfel et al., 1996), and in the rat hippocampus in vivo (Lindholm et al., 1994). Taken together with the present study, results from experiments examining effects of exogenously administered trophic factors must be interpreted with caution because some effects could result indirectly from augmentation of production of other growth factors. The further investigation of influences on trophic factor expression by cytokines and trophic factors will provide insight into the complex regulation and interaction of trophic molecules.

The enhanced growth of corticospinal axons observed in the present experiment may have resulted directly from LIF augmentation of injured corticospinal axon growth or indirectly from LIF-modulated increases in NT-3 expression. Previous findings support a potential direct role for LIF action on corticospinal axons. (1) CNTF receptors, which mediate signal transduction using the same receptor components as LIF (plus the additional CNTF binding component CNTF receptor $\alpha$ ), are present on cortical layer V neurons (Ip et al., 1993a). CNTF-responsive neuronal populations generally display identical responses to LIF (Martinou et al., 1992; Rao et al., 1992; Fann and Patterson, 1993, 1994). (2) CNTF promotes corticospinal motoneuron survival in vitro (Magal et al., 1993). CNTF has also been reported to protect corticospinal motor neurons from intracortical axotomy (Dale et al., 1995), although the latter study did not determine whether CNTF might have modulated expression of other neurotrophins such as NT-3 that also act on corticospinal axons. On the other hand, LIF could also have indirectly influenced corticospinal axonal growth in the present experiment, because LIF-secreting cell grafts upregulated NT-3 expression, and NT-3 is a corticospinal axon growth factor (Schnell et al., 1994; Yee and O'Leary, 1996). We have previously reported that the cellular delivery of NT-3 to the lesioned spinal cord augments corticospinal axonal growth (Grill et al., 1997), suggesting that the present findings could have resulted from augmented NT-3 release at the injury site.

The effects of cellular LIF delivery on corticospinal axons have been referred to in this report as enhanced "growth." This generic term is used to reflect the possibility that either axonal regeneration (i.e., growth from the tips of injured axons), sprouting 


\section{LIF}
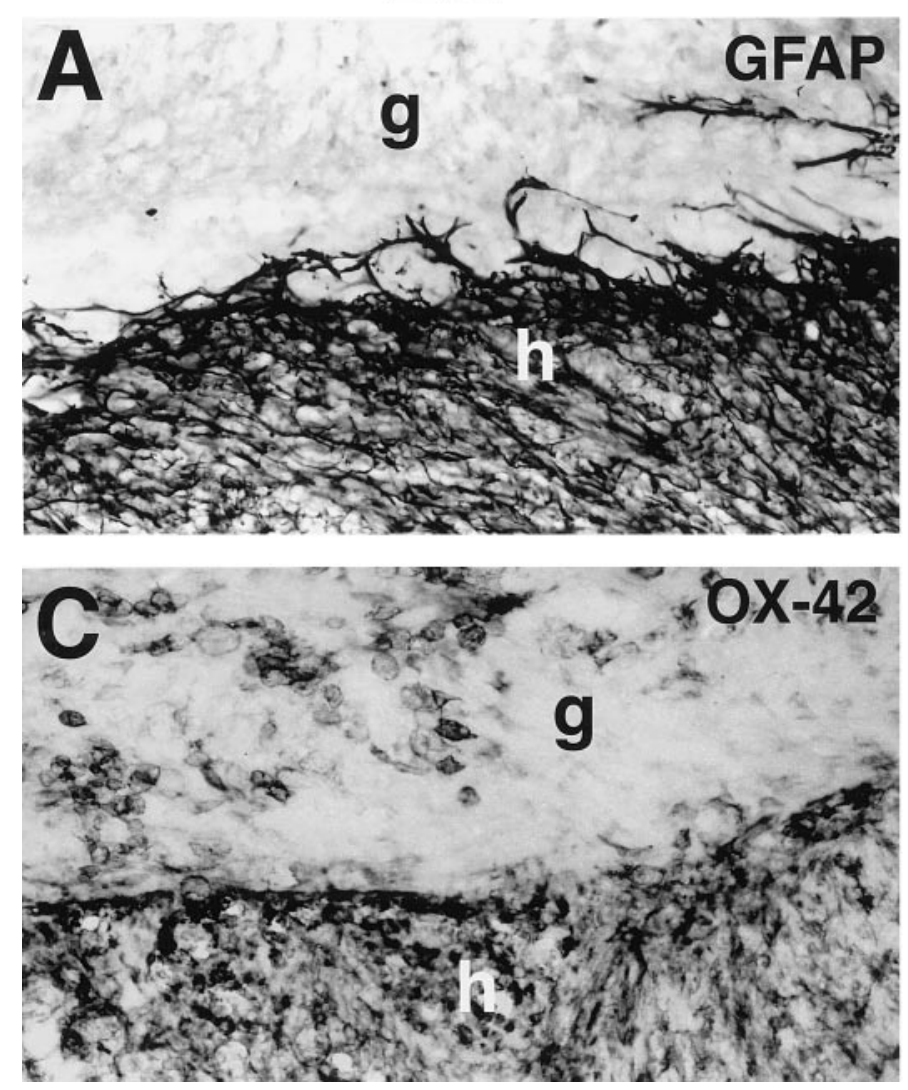

\section{Control}
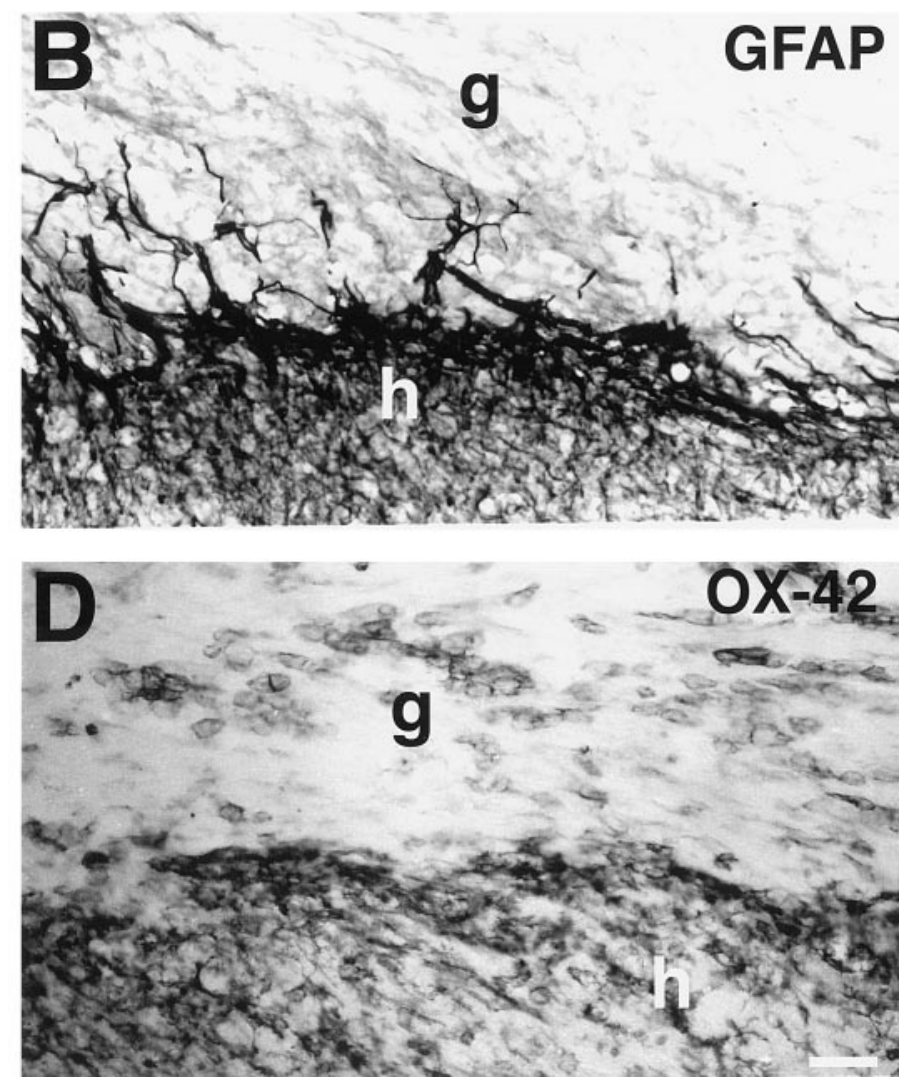

Figure 8. Microglial and astroglial activation at the host/graft interface. $A, B$, GFAP-immunolabeled processes are present at the host $(h) / g r a f t ~(g)$ interface, but extend relatively few processes into the graft. Qualitative and quantitative differences in GFAP labeling are not evident when comparing LIF-secreting $(A)$ and control $(B)$ grafts. Macrophages/microglia surround and invade $(C)$ LIF-secreting and $(D)$ control grafts to a similar extent, as shown by OX-42 labeling. Scale bar, $55 \mu \mathrm{m}$.

(i.e., growth from neighboring, uninjured axons), or both may have occurred. Evidence for the presence of regeneration in this paradigm is provided in Figure $5 B$, wherein axonal extension directly from transected tips of corticospinal axons is shown. Axonal sprouting also occurs and is evident in Figure $4 C$ : enhanced CST labeling is observed in gray matter ventral and slightly rostral to the injury site. Either or both of these mechanisms may have contributed to the increased density of CST axons at the lesion site in LIF-grafted subjects, where axonal density measurements were made (Figs. $4 E, F, 5 A$ ).

In the present experiment, corticospinal axons were unable to penetrate the collagen graft despite the presence of a growthpromoting stimulus provided by the LIF-secreting fibroblasts. This finding is similar to our observations that grafts of NT-3producing fibroblasts to the injured spinal cord elicit CST axonal growth in spinal gray matter rather than in white matter or into the graft itself (Grill et al., 1997). This lack of axonal penetration might be caused by inhibitory molecules expressed at the host/ graft interface or by the nonpermissiveness of the extracellular milieu in the graft environment, which contains abundant amounts of fibronectin and collagen. Although CST axons are unable to penetrate a cellular graft producing growth-promoting trophic molecules, other populations of axons successfully penetrate these grafts (Fig. 6) and specifically associate with extracellular molecules of the graft (Tuszynski et al., 1996). For example, sensory axons robustly penetrate grafts of fibroblasts transduced to express NGF, and associate with collagen within the grafts (Tuszynski et al., 1996). Sensory axons also penetrated LIFsecreting grafts in the present experiment, but not to an extent that differed significantly from control grafts. Thus, the extent and direction of axonal growth after adult CNS injury appears to be determined both by growth factor gradients and by the nature of the local extracellular matrix.

Further indirect mechanisms for LIF-induced modulation of CNS axonal growth are possible through alteration of glial or inflammatory responses after injury. In the present experiment, an effect of cellular LIF delivery on astrocytic responses was not detected at qualitative or quantitative levels, nor were qualitative changes in OX-42 labeling of macrophages/microglia detected. These in vivo results confirm a recent report that LIF does not enhance proliferation of microglia cultivated on an astrocyte monolayer in vitro (Kloss et al., 1997). However, as mentioned in the introductory remarks, findings from LIF- and LIF-receptorknockout mice indicate that LIF regulates GFAP expression in the CNS (Ware et al., 1995; Bugga et al., 1998). CNTF, another member of the cytokine family of growth factors, also modulates astrogliosis and microglial proliferation (Ip et al., 1993b; Kahn et al., 1995; Lisovoski et al., 1997). Because the spinal cord injury upregulated GFAP immunoreactivity in the present experiment, it is possible that an effect of LIF delivery that exceeded the 
robust stimulus of the spinal cord injury itself was not detectable. LIF delivery could also enhance or inhibit the inflammatory activity of macrophages or neutrophils (Ulich et al., 1994; Patterson et al., 1997; Banner et al., 1998), which may influence axonal growth after injury. Although qualitative analysis failed to yield evidence of LIF-induced changes in a macrophage/microglia marker in the present experiment, subtle differences might have been below the threshold of detectability with the techniques used, and effects on other components of the inflammatory response have not been excluded. The fact that only female rats were used in this study could also influence these results, because inflammatory responses can vary between sexes. Although the present findings have not provided direct evidence of a role for cellular LIF delivery in modulating glial responses in the injured adult CNS, it is possible that glia were the source of augmented NT-3 expression detected in recipients of LIF-secreting grafts.

In summary, results from this study support a role for LIF in modulating responses of the CNS to injury. LIF can increase neurotrophic factor expression and promote the growth of a specific class of injured axons in the CNS. The interplay of overlapping and distinct actions of classic neurotrophic factors and cytokine growth factors collectively appear to determine cell fate, axonal growth, glial activation, and inflammatory responses to injury. The experimental manipulation of these factors, as demonstrated in this and other experiments, can provide a means of enhancing the degree of CNS recovery from injury.

\section{REFERENCES}

Aloisi F, Rosa S, Testa U, Bonsi P, Russo G, Peschle C, Levi G (1994) Regulation of leukemia inhibitory factor synthesis in cultured human astrocytes. J Immunol 152:5022-5031.

Apfel SC, Wright DE, Wiideman AM, Dormia C, Snider WD, Kessler JA (1996) Nerve growth factor regulates the expression of brain-derived neurotrophic factor mRNA in the peripheral nervous system. Mol Cell Neurosci 7:134-142.

Arakawa Y, Sendtner M, Thoenen H (1990) Survival effect of ciliary neurotrophic factor (CNTF) on chick embryonic motoneurons in culture: comparison with other neurotrophic factors and cytokines. J Neurosci 10:3507-3515.

Banner LR, Patterson PH (1994) Major changes in the expression of the mRNAs for cholinergic differentiation factor/leukemia inhibitory factor and its receptor after injury to adult peripheral nerves and ganglia. Proc Natl Acad Sci USA 91:7109-7113.

Banner LR, Moayeri NN, Patterson PH (1997) Leukemia inhibitory factor is expressed in astrocytes following cortical brain injury. Exp Neurol 147:1-9.

Banner LR, Patterson PH, Allchorne A, Poole S, Woolf CJ (1998) Leukemia inhibitory factor is an anti-inflammatory and analgesic cytokine. 18:5456-5462.

Barres BA, Schmid R, Sendtner M, Raff MC (1993) Multiple extracellular signals are required for long-term oligodendrocyte survival. Development 116:283-295.

Bugga L, Gadient RA, Kwan K, Stewart CL, Patterson PH (1998) Analysis of neuronal and glial phenotypes in brains of mice deficient in leukemia inhibitory factor. J Neurobiol 36:509-524.

Cannosa M, Griesbeck O, Berninger B, Campana G, Kolbeck R, Thoenen H (1997) Neurotrophin release by neurotrophins: implications for activity-dependent neuronal plasticity. Proc Natl Acad Sci USA 94:13279-13286.

Cheema SS, Richards L, Murphy M, Bartlett PF (1994a) Leukemia inhibitory factor prevents the death of axotomised sensory neurons in the dorsal root ganglia of the neonatal rat. J Neurosci Res 37:213-218.

Cheema SS, Richards LJ, Murphy M, Bartlett PF (1994b) Leukaemia inhibitory factor rescues motoneurones from axotomy-induced cell death. NeuroReport 5:989-992.

Curtis R, Scherer SS, Somogyi R, Adryan KM, Ip NY, Zhu Y, Lindsay RM, DiStefano PS (1994) Retrograde axonal transport of LIF is increased by peripheral nerve injury: correlation with increased LIF expression in distal nerve. Neuron 12:191-204.
Dale SM, Kuang RZ, Wei X, Varon S (1995) Corticospinal motor neurons in the adult rat: degeneration after intracortical axotomy and protection by ciliary neurotrophic factor (CNTF). Exp Neurol 135:67-73.

Davis S, Aldrich TH, Ip NY, Stahl N, Scherer S, Farruggella T, DiStefano PS, Curtis R, Panayotatos N, Gascan H, Chevalier S, Yamcopoulos GD (1993) Released form of CNTF receptor alpha component as a soluble mediator of CNTF responses. Science 259:1736-1739.

Eide FF, Lowenstein DH, Reichardt LF (1993) Neurotrophins and their receptors: current concepts and implications for neurologic disease. Exp Neurol 121:200-214.

Fann MJ, Patterson PH (1993) A novel approach to screen for cytokine effects on neuronal gene expression. J Neurochem 61:1349-1355.

Fann MJ, Patterson PH (1994) Neuropoietic cytokines and activin A differentially regulate the phenotype of cultured sympathetic neurons. Proc Natl Acad Sci USA 91:43-47.

Figueiredo BC, Plüss K, Skup M, Otten U, Cuello AC (1995) Acidic FGF induces NGF and its mRNA in the injured neocortex of adult animals. Brain Res Mol Brain Res 33:1-6.

Funakoshi H, Frisen J, Barbany G, Timmusk T, Zachrisson O, Verge VM, Persson H (1993) Differential expression of mRNAs for neurotrophins and their receptors after axotomy of the sciatic nerve. J Cell Biol 123:455-465.

Gard AL, Burrell MR, Pfeiffer SE, Rudge JS, Williams WC (1995) Astroglial control of oligodendrocyte survival mediated by PDGF and leukemia inhibitory factor-like protein. Development 121:2187-2197.

Grill R, Murai K, Blesch A, Gage FH, Tuszynski MH (1997) Cellular delivery of neurotrophin-3 promotes corticospinal axonal growth and partial functional recovery after spinal cord injury. J Neurosci 17:5560-5572.

Hagg T, Varon S, Louis JC (1993) Ciliary neurotrophic factor (CNTF) promotes low-affinity nerve growth factor receptor and CD4 expression by rat CNS microglia. J Neuroimmunol 48:177-187.

Hendry IA, Murphy M, Hilton DJ, Nicola NA, Bartlett PF (1992) Binding and retrograde transport of leukemia inhibitory factor by the sensory nervous system. J Neurosci 12:3427-3434.

Ip NY, McClain J, Barrezueta NX, Aldrich TH, Pan L, Li Y, Wiegand SJ, Friedman B, Davis S, Yancopoulos GD (1993a) The alpha component of the CNTF receptor is required for signaling and defines potential CNTF targets in the adult and during development. Neuron 10:89-102.

Ip NY, Wiegand SJ, Morse J, Rudge JS (1993b) Injury-induced regulation of ciliary neurotrophic factor mRNA in the adult rat brain. Eur J Neurosci 5:25-33.

Kahn MA, de Vellis J (1994) Regulation of an oligodendrocyte progenitor cell line by the interleukin-6 family of cytokines. Glia 12:87-98.

Kahn MA, Ellison JA, Speight GJ, de Vellis J (1995) CNTF regulation of astrogliosis and the activation of microglia in the developing rat central nervous system. Brain Res 685:55-67.

Kiefer R, Lindholm D, Kreutzberg GW (1993) Interleukin-6 and transforming growth factor-beta 1 mRNAs are induced in rat facial nucleus following motoneuron axotomy. Eur J Neurosci 5:775-781.

Kitamura T, Tange T, Terasawa T, Chiba S, Kuwaki T, Miyagawa K, Piao YF, Miyazono K, Urabe A, Takaku F (1989) Establishment and characterization of a unique human cell line that proliferates dependently on GM-CSF, IL-3, or erythropoietin. J Cell Physiol 140:323-334.

Kloss CU, Kreutzberg GW, Raivich G (1997) Proliferation of ramified microglia on an astrocyte monolayer: characterization of stimulatory and inhibitory cytokines. J Neurosci Res 49:248-254.

Korsching S (1993) The neurotrophic factor concept: a reexamination. J Neurosci 13:2739-2748.

Kurek JB, Austin L, Cheema SS, Bartlett PF, Murphy M (1996) Upregulation of leukaemia inhibitory factor and interleukin-6 in transected sciatic nerve and muscle following denervation. Neuromuscul Disord 6:105-114.

Lewin GR, Barde YA (1996) Physiology of the neurotrophins. Annu Rev Neurosci 19:289-317.

Lindholm D, da Penha Berzaghi M, Cooper J, Thoenen H, Castrén E (1994) Brain-derived neurotrophic factor and neurotrophin-4 increase neurotrophin-3 expression in the rat hippocampus. Int J Dev Neurosci 12:745-751.

Lisovoski F, Akli S, Peltekian E, Vigne E, Haase G, Perricaudet M, Dreyfus PA, Kahn A, Peschanski M (1997) Phenotypic alteration of astrocytes induced by ciliary neurotrophic factor in the intact adult brain, as revealed by adenovirus-mediated gene transfer. J Neurosci 17:7228-7236. 
Magal E, Louis JC, Oudega M, Varon S (1993) CNTF promotes the survival of neonatal rat corticospinal neurons in vitro. NeuroReport 4:779-782.

Martinou JC, Martinou I, Kato AC (1992) Cholinergic differentiation factor $(\mathrm{CDF} / \mathrm{LIF})$ promotes survival of isolated rat embryonic motoneurons in vitro. Neuron 8:737-744.

Mayer M, Bhakoo K, Noble M (1994) Ciliary neurotrophic factor and leukemia inhibitory factor promote the generation, maturation and survival of oligodendrocytes in vitro. Development 120:143-153.

Minami M, Kuraishi Y, Satoh M (1991) Effects of kainic acid on messenger RNA levels of IL-1 beta, IL-6, TNF alpha and LIF in the rat brain. Biochem Biophys Res Commun 176:593-598.

Murphy Jr GM, Song Y, Ong E, Lee YL, Schmidt KG, Bocchini V, Eng LF (1995) Leukemia inhibitory factor mRNA is expressed in cortical astrocyte cultures but not in an immortalized microglial cell line. Neurosci Lett 184:48-51.

Murphy M, Reid K, Hilton DJ, Bartlett PF (1991) Generation of sensory neurons is stimulated by leukemia inhibitory factor. Proc Natl Acad Sci USA 88:3498-3501.

Murphy M, Reid K, Ford M, Furness JB, Bartlett PF (1994) FGF2 regulates proliferation of neural crest cells, with subsequent neuronal differentiation regulated by LIF or related factors. Development 120:3519-3528.

Murphy M, Dutton R, Koblar S, Cheema S, Bartlett P (1997) Cytokines which signal through the LIF receptor and their actions in the nervous system. Prog Neurobiol 52:355-378.

Patterson PH (1994) Leukemia inhibitory factor, a cytokine at the interface between neurobiology and immunology. Proc Natl Acad Sci USA 91:7833-7835.

Patterson PH, Kou S-Y, Sugiura S, Lahav R, Banner LR (1997) LIF coordinates neuronal and inflammatory responses to nerve injury. Soc Neurosci Abstr 23:997.

Rao MS, Tyrrell S, Landis SC, Patterson PH (1992) Effects of ciliary neurotrophic factor (CNTF) and depolarization on neuropeptide expression in cultured sympathetic neurons. Dev Biol 150:281-293.

Rao MS, Sun Y, Escary JL, Perreau J, Tresser S, Patterson PH, Zigmond RE, Brulet P, Landis SC (1993) Leukemia inhibitory factor mediates an injury response but not a target-directed developmental transmitter switch in sympathetic neurons. Neuron 11:1175-1185.

Richards LJ, Kilpatrick TJ, Dutton R, Tan SS, Gearing DP, Bartlett PF, Murphy M (1996) Leukaemia inhibitory factor or related factors promote the differentiation of neuronal and astrocytic precursors within the developing murine spinal cord. Eur J Neurosci 8:291-299.

Schnell L, Schwab ME (1993) Sprouting and regeneration of lesioned corticospinal tract fibres in the adult rat spinal cord. Eur J Neurosci 5:1156-1171.
Schnell L, Schneider R, Kolbeck R, Barde YA, Schwab ME (1994) Neurotrophin-3 enhances sprouting of corticospinal tract during development and after adult spinal cord lesion. Nature 367:170-173.

Sendtner M, Gotz R, Holtmann B, Escary JL, Masu Y, Carroll P, Wolf E, Brem G, Brulet P, Thoenen H (1996) Cryptic physiological trophic support of motoneurons by LIF revealed by double gene targeting of CNTF and LIF. Curr Biol 6:686-694.

Sun Y, Zigmond RE (1996) Involvement of leukemia inhibitory factor in the increases in galanin and vasoactive intestinal peptide mRNA and the decreases in neuropeptide $\mathrm{Y}$ and tyrosine hydroxylase mRNA in sympathetic neurons after axotomy. J Neurochem 67:1751-1760.

Sun Y, Rao MS, Zigmond RE, Landis SC (1994) Regulation of vasoactive intestinal peptide expression in sympathetic neurons in culture and after axotomy: the role of cholinergic differentiation factor/leukemia inhibitory factor. J Neurobiol 25:415-430.

Thaler CD, Suhr L, Ip N, Katz DM (1994) Leukemia inhibitory factor and neurotrophins support overlapping populations of rat nodose sensory neurons in culture. Dev Biol 161:338-344.

Tham S, Dowsing B, Finkelstein D, Donato R, Cheema SS, Bartlett PF, Morrison WA (1997) Leukemia inhibitory factor enhances the regeneration of transected rat sciatic nerve and the function of reinnervated muscle. J Neurosci Res 47:208-215.

Thoenen H (1995) Neurotrophins and neuronal plasticity. Science 270:593-598.

Tuszynski MH, Gabriel K, Gage FH, Suhr S, Meyer S, Rosetti A (1996) Nerve growth factor delivery by gene transfer induces differential outgrowth of sensory, motor, and noradrenergic neurites after adult spinal cord injury. Exp Neurol 137:157-173.

Ulich TR, Fann MJ, Patterson PH, Williams JH, Samal B, Del Castillo J, Yin S, Guo K, Remick DG (1994) Intratracheal injection of LPS and cytokines. V. LPS induces expression of LIF and LIF inhibits acute inflammation. Am J Physiol 267:L442-446.

Ware CB, Horowitz MC, Renshaw BR, Hunt JS, Liggitt D, Koblar SA, Gliniak BC, McKenna HJ, Papayannopoulou T, Thoma B, Cheng L, Donovan PJ, Peschon JJ, Bartlett PF, Willis CR, Wright BD, Carpenter MK, Davison BL, Gearing DP (1995) Targeted disruption of the low-affinity leukemia inhibitory factor receptor gene causes placental, skeletal, neural and metabolic defects and results in perinatal death. Development 121:1283-1299.

Yamamori T, Fukada K, Aebersold R, Korsching S, Fann MJ, Patterson PH (1989) The cholinergic neuronal differentiation factor from heart cells is identical to leukemia inhibitory factor. Science 246:1412-1416.

Yee KT, O'Leary DDM (1996) NT-3 and trkC expression patterns suggest their role in the development of corticospinal axon projections to the brainstem and spinal cord. Soc Neurosci Abstr 22:1468. 